\title{
MATHEMATICAL STUDY OF NON-NEWTONIAN NANOFLUID TRANSPORT PHENOMENA FROM AN ISOTHERMAL SPHERE
}

\author{
CH. Amanulla ${ }^{\mathrm{a}, \mathrm{b}}$, N. Nagendra ${ }^{\mathrm{a}}$, M. Surya Narayana Reddy ${ }^{\mathrm{b}}$, A. Subba Rao ${ }^{\mathrm{a}}$, O. Anwar Bég ${ }^{\mathrm{c}}$ \\ ${ }^{a}$ Department of Mathematics, Madanapalle Institute of Technology and Science, Madanapalle-517325, A. P, India. \\ ${ }^{b}$ Department of Mathematics, JNTUA College of Engineering, Pulivendula-516390, A. P, India. \\ ${ }^{c}$ Fluid Mechanics, Nanosystems and Propulsion, Aeronautical and Mechanical Engineering, School of Computing, Science and Engineering, \\ Newton Building, University of Salford, Manchester M54WT, United Kingdom.
}

\begin{abstract}
In this article, the heat, momentum and mass (species) transfer in external boundary layer flow of Casson nanofluid from an isothermal sphere surface is studied theoretically. The effects of Brownian motion and thermophoresis are incorporated in the model in the presence of both heat and nanoparticle mass transfer. The governing partial differential equations (PDEs) are transformed into highly nonlinear, coupled, multi-degree non-similar partial differential equations consisting of the momentum, energy and concentration equations via appropriate non-similarity transformations. These transformed conservation equations are solved subject to appropriate boundary conditions with a second order accurate finite difference method of the implicit type. The influences of the emerging parameters i.e. Casson fluid parameter $(\beta)$, Buoyancy ratio parameter $(N)$, Brownian motion parameter $(\mathrm{Nb})$ and thermophoresis parameter $(\mathrm{Nt})$, Lewis number $(\mathrm{Le})$ and Prandtl number $(\mathrm{Pr})$ on velocity, temperature and nano-particle concentration distributions are illustrated graphically and interpreted at length. Validation of solutions with a Nakamura tridiagonal method has been included.

Keywords: Nanoparticles; Species diffusion; Steady flow; Casson viscoplastic model; Keller-box numerical method; Heat transfer.
\end{abstract}

\section{INTRUDUCTION}

The word "nanotechnology" was probably used for the first time by the Japanese scientist Norio Taniguchi in 1974. K. Eric Drexler is credited with initial theoretical work in the field of nanotechnology. The term nanotechnology was used by Drexler in his 1986 book "Engines of creation: The coming era of nanotechnology". Drexler's idea of nanotechnology is referred to as molecular nanotechnology (2011). Earlier the great theoretical physicist Richard Feynman predicted nanotechnology in 1959. In the 1980s and 1990s new nanomaterials were discovered and nanofluids emerged as a result of the experiments intended to increase the thermal conductivity of liquids. The birth of nanofluids is attributed to the revolutionary idea of adding solid particles into fluids to increase the thermal conductivity. This innovative idea was put forth by the Scottish physicist J.C. Maxwell as early as 1873 .

Nanofluids have evolved into a very exciting and rich frontier in modern nano-technology. The excitement can be attributed to the robustness of the concept of nanofluids and the plethora of different applications of this technology (2010). The properties of nanofluids need a lot of fine tuning, many seemingly contradicting studies need clarity and validation. Nanofluids have potential applications in microelectronics, fuel cells, rocket propulsion, environmental detoxification, spray coating of aircraft wings, pharmaceutical suspensions, medical sprays etc. These applications of nanofluids are largely attributable to the enhanced thermal conductivity and Brownian motion dynamics which can be exploited to immense benefit. Nanomaterials work efficiently as new energy materials since they incorporate suspended particles with size as the same as or smaller than the size of de Broglie wave (2009). The use of nanoparticles is now a subject of abundant studies, and aspects of particular interest are Brownian motion and thermophoretic transport. Nanofluids constitute a new class of heat transfer fluids comprising a conventional base fluid and nano-particles. The nanoparticles are utilized to enhance the heat transfer performance of the base fluids (1995). The cooling rate requirements cannot be obtained by the ordinary heat transfer fluids because their thermal conductivity is not adequate. Brownian motion of the nanoparticles enhances the thermal conductivity of base fluids, although there may be many more mechanisms at work which exert a contribution. The concept of nanofluids was introduced by Choi (1995) wherein he proposed the suspension of nanoparticles in a base fluid such as water, oil, and ethylene glycol. Buongiorno (2006) attempted to explain the increase in the thermal conductivity of such fluids and developed a model that emphasized the key mechanisms in laminar flow as being particle Brownian motion and thermophoresis.

In recent years with the development of hydrophobic surfaces, slip flows have garnered some attention in nanofluid dynamics. Furthermore, the non-Newtonian properties of different nanofluid suspensions have also attracted interest in simulating rheological behavior with different models. Mahatha et al. (2016) investigated dissipative effects in hydromagnetic boundary layer nanofluid flow past a stretching sheet with Newtonian heating. They found that an increase in the Biot number brings an increase in the nanofluids temperature and nanoparticle volume fraction. Due to convective heat transfer from the hot fluid to the surface of the sheet, the sheet gets heated which in turn increases the heat transfer rate from the sheet to the fluid. Subba Rao and Nagendra (2015) investigated thermal radiation effects on Oldroyd-B viscoelastic nanofluid flow from a stretching sheet in a non-Darcy porous medium. They analyzed the behavior of nano particles on temperature and concentration distributions in detail. Uddin et al. (2016) analyzed anisotropic slip effects on nanofluid bioconvection boundary layers from a translating 
sheet using MAPLE symbolic quadrature and Lie group methods. Rana et al. (2016) used a high-penalty finite element method to simulate two-dimensional flow dissipative viscoelastic nanofluid polymeric boundary layer stretching sheet flow, employing the ReinerRivlin second grade non-Newtonian model. They showed that greater polymer fluid viscoelasticity accelerates the flow and increasing Brownian motion and thermophoresis enhances temperatures and reduces heat transfer rates (local Nusselt numbers. Malik et al. (2014) used the Runge-Kutta Fehlberg method to obtain numerical solutions for steady thermal boundary layer flow of a Casson nanofluid flowing over a vertical radially exponentially-stretching cylinder. Many such studies have been communicated and have usually adopted the socalled "active control" boundary condition, based on the KuznetsovNield formulation (2010) for natural convective boundary layer flow of a nanofluid over a vertical surface featuring Brownian motion and thermophoresis. However, Kuznetsov and Nield (2014) re-visited their original model, refining this formulation with passive control of nanofluid particle fraction at the boundary rather than active control to be more physically realistic. This recent boundary condition provides one of the motivations for the present research.

The above studies were generally confined to internal transport However external boundary layer convection flows also find applications in many technological systems including enrobing polymer coating processes, heat exchanger design, solar collector architecture etc. Prasad et al. (2015) studied two-dimensional nanofluid boundary layer flow from a spherical geometry embedded in porous media with a finite difference scheme. Mahesh and Reddy (2015) studied natural convection flow of a non-Newtonian nanofluid past a sphere. They also found that the friction factor and heat transfer rates decrease as the cross viscosity parameter increases. Chamkha et al. (2010) analyzed the natural convection past a sphere embedded in a non-Darcy porous medium saturated by a nanofluid. Bég et al. (2015) derived both homotopy and Adomian decomposition numerical solutions for transient stagnation-point heat and mass transfer from a rotating sphere.

The present work, motivated by applications in enrobing dynamics of magnetic nanomaterials (2011), examines theoretically and computationally the steady-state transport phenomena in Casson nanofluid flow past an Isothermal sphere. Mathematical modelling is developed to derive the equations of continuity, momentum, energy and species conservation, based on the Buonjiornio nanofluid model (2006). The partial differential boundary layer equations are then transformed into a system of dimensionless non-linear coupled differential boundary layer equations, which is solved with the robust second order accurate Keller box implicit finite difference method. The present work extends significantly earlier simulations of Hussain et al. (2015) (who consider an exponentially stretching surface) to the case of a isothermal sphere. An extensive parametric analysis of the influence of a number of parameters (Brownian motion, thermophoresis, Casson non-Newtonian, stream wise coordinate) on thermo-diffusive characteristics is conducted. The simulations are also relevant to calendaring in pseudo-plastic materials fabrication (2006).

\section{MATHEMATICAL MODEL}

We examine steady buoyancy-driven convection heat transfer flow of Casson nanofluid from an Isothermal Sphere. Figure 1 shows the flow model and associated coordinate system. The nanofluid fluid is taken to be incompressible and a homogenous dilute solution. The $\mathrm{x}$-axis taken along the isothermal sphere surface measured from the origin and the $\mathrm{y}$-axis is measured normal to the surface, $r=a \sin \left(\frac{x}{a}\right)$ with ' $\mathrm{a}$ ' denoting the radius of the sphere. The gravitational acceleration, $\boldsymbol{g}$ acts downwards. Both the sphere and the fluid are maintained initially at the same temperature. Instantaneously they are raised to a temperature
$T_{w}>T_{\infty}$ i.e. the ambient temperature of the fluid which remains unchanged.

The appropriate constitutive equations for the Casson nonNewtonian model are:

$$
\tau_{i j}=\left\{\begin{array}{l}
2\left(\mu_{B}+\frac{p_{y}}{\sqrt{2 \pi}}\right) e_{i j}, \pi \geq \pi_{c} \\
2\left(\mu_{B}+\frac{p_{y}}{\sqrt{2 \pi_{c}}}\right) e_{i j}, \pi<\pi_{c}
\end{array}\right.
$$

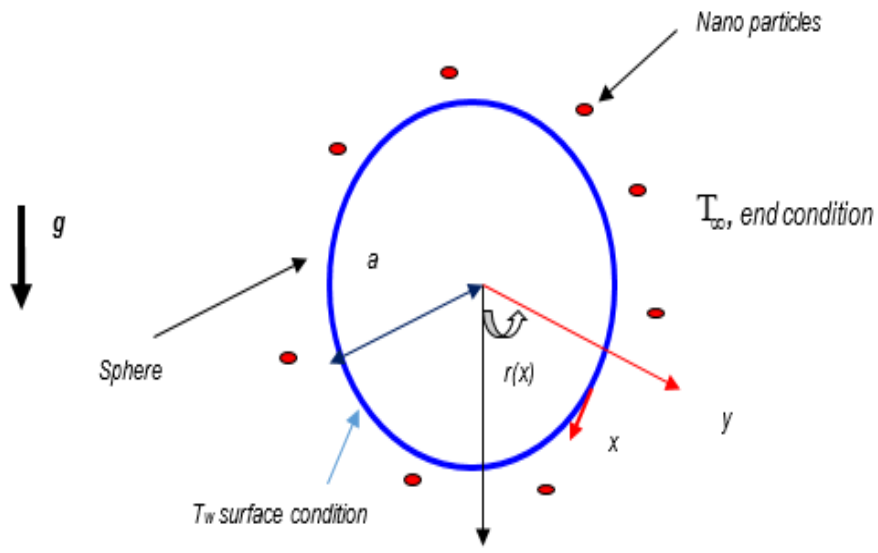

Fig. 1 Physical model and coordinate system

In which $\pi=e_{i j} e_{i j}$ and $e_{i j}$ is the $(\mathrm{i}, \mathrm{j})^{\text {th }}$ component of deformation rate, $\pi$ denotes the product of the component of deformation rate with itself, $\pi_{\mathrm{c}}$ shows a critical value of this product based on the non-Newtonian model, $\mu_{B}$ the plastic dynamic viscosity of non-Newtonian fluid and $p_{y}$ the yield stress of fluid.

The Casson model, although relatively simple, is a robust viscoplastic model and describes accurately the shear stress-strain behavior of certain industrial polymers in which flow is not possible prior to the attainment of a critical shear stress. Unlike the Bingham viscoplastic model which has a linear shear rate, the Casson model has a non-linear shear rate. Casson fluid theory was originally propounded to simulate shear thinning (viscosity is reduced with greater shear rates) liquids containing rod-like solids and is equally popular in analysing inks, emulsions, food stuffs (chocolate melts), certain gels and paints (1959). More recently it has been embraced in advanced polymeric flow processing (1994). Incorporating the Casson terms and applying the Buonjiorni nanofluid model, the governing conservation equations, in primitive form, for the regime under investigation i.e. mass continuity, momentum, energy and species, can be written as follows:

$$
\begin{aligned}
& \frac{\partial(u r)}{\partial x}+\frac{\partial(v r)}{\partial y}=0 \\
& u \frac{\partial u}{\partial x}+v \frac{\partial u}{\partial y}=v\left(1+\frac{1}{\beta}\right) \frac{\partial^{2} u}{\partial y^{2}}+\left(g \beta_{T}\left(T-T_{\infty}\right)+g \beta_{C}\left(C-C_{\infty}\right)\right) \sin \left(\frac{x}{a}\right)
\end{aligned}
$$


$u \frac{\partial T}{\partial x}+v \frac{\partial T}{\partial y}=\alpha \frac{\partial^{2} T}{\partial y^{2}}+\tau\left(D_{B} \frac{\partial C}{\partial y} \frac{\partial T}{\partial y}+\frac{D_{T}}{T_{\infty}}\left(\frac{\partial T}{\partial y}\right)^{2}\right)$

$u \frac{\partial C}{\partial x}+v \frac{\partial C}{\partial y}=D_{B} \frac{\partial^{2} C}{\partial y^{2}}+\frac{D_{T}}{T_{\infty}} \frac{\partial^{2} T}{\partial y^{2}}$

The boundary conditions imposed at the sphere surface and in the free stream are:

At $y=0, u=0, v=0, T=T_{w}, C=C_{w}$

As $y \rightarrow \infty, u \rightarrow 0, v \rightarrow 0, T \rightarrow T_{\infty}, C \rightarrow C_{\infty}$

The stream function $\psi$ is defined by the Cauchy-Riemann equations, $r u=\partial(r \psi) / \partial y$ and $r v=-\partial(r \psi) / \partial x$, and therefore, the continuity equation is automatically satisfied. In order to write the governing equations and the boundary conditions in dimensionless form, the following non-dimensional quantities are introduced.

$$
\begin{gathered}
\xi=\frac{x}{a}, \quad \eta=\frac{y}{a}(G r)^{1 / 4}, \tau=\frac{(\rho c)_{p}}{(\rho c)_{f}}, f(\xi, \eta)=\frac{\psi}{r v(G r)^{1 / 4}} \\
\theta(\xi, \eta)=\frac{T-T_{\infty}}{T_{w}-T_{\infty}}, \phi(\xi, \eta)=\frac{C-C_{\infty}}{C_{w}-C_{\infty}}, G r=\frac{g \beta_{T}\left(T_{w}-T_{\infty}\right) a^{3}}{v^{3}}
\end{gathered}
$$

The transformed boundary layer equations for momentum, energy and concentration emerge as:

$$
\begin{aligned}
& \left(1+\frac{1}{\beta}\right) f^{\prime \prime \prime}+(1+\xi \cot \xi) f f^{\prime \prime}-\frac{1}{2} f^{\prime^{2}}+\frac{\sin \xi}{\xi}(\theta+N \phi) \\
& =\xi\left(f^{\prime} \frac{\partial f^{\prime}}{\partial \xi}-f^{\prime \prime} \frac{\partial f}{\partial \xi}\right) \\
& \frac{\theta^{\prime \prime}}{\operatorname{Pr}}+(1+\xi \cot \xi) f \theta^{\prime}+N_{b} \phi^{\prime} \theta^{\prime}+N_{t} \theta^{\prime 2}=\xi\left(f^{\prime} \frac{\partial \theta}{\partial \xi}-\theta^{\prime} \frac{\partial f}{\partial \xi}\right) \\
& \frac{\phi^{\prime \prime}}{L e}+(1+\xi \cot \xi) f \phi^{\prime}+\frac{1}{L e} \frac{N_{b}}{N_{t}} \theta^{\prime \prime}=\xi\left(f^{\prime} \frac{\partial \phi}{\partial \xi}-\phi^{\prime} \frac{\partial f}{\partial \xi}\right)
\end{aligned}
$$

The corresponding transformed dimensionless boundary conditions are:

At $\eta=0, f=0, f^{\prime}=0, \theta=1, \phi=1$

As $\eta \rightarrow \infty, f^{\prime} \rightarrow 0, \theta \rightarrow 0, \phi \rightarrow 0$

Where

$$
\begin{aligned}
& \operatorname{Pr}=\frac{\gamma}{\alpha}, N t=\frac{(\rho c)_{p} D_{T}\left(T_{w}-T_{\infty}\right)}{(\rho c)_{f} \gamma T_{\infty}}, N=\frac{\beta_{T}\left(T_{w}-T_{\infty}\right)}{\beta_{C}\left(C_{w}-C_{\infty}\right)} \\
& L e=\frac{\gamma}{D_{B}}, N b=\frac{(\rho c)_{p} D_{B}\left(C_{w}-C_{\infty}\right)}{(\rho c)_{f} \gamma}
\end{aligned}
$$

All other parameters are defined in the nomenclature. The skinfriction coefficient (sphere surface shear stress function), the local Nusselt number (heat transfer rate) and Sherwood number (mass transfer rate) can be defined using the transformations described above with the following expressions:

$$
\begin{aligned}
& \frac{1}{2} G r^{-3 / 4} C_{f}=\left(1+\frac{1}{\beta}\right) \xi f^{\prime \prime}(\xi, 0) \\
& G r^{-1 / 4} N u=-\theta^{\prime}(\xi, 0) \\
& G r^{-1 / 4} S h=-\phi^{\prime}(\xi, 0)
\end{aligned}
$$

\section{NUMERICAL SOLUTION WITH KELLER BOX IMPLICT METHOD}

The strongly coupled, nonlinear conservation equations do not admit analytical (closed-form) solutions. An elegant, implicit difference finite difference numerical method developed by Keller (1970) is therefore adopted to solve the general flow model defined by equations (8) - (10) with boundary conditions (11). This method is especially appropriate for boundary layer flow equations which are parabolic in nature. It remains one of the most widely applied computational methods in viscous fluid dynamics. Recent problems which have used Keller's method include radiative magnetic forced convection flow (2006), stretching sheet hydromagnetic flow (2013), Cylindrical hydromagnetic flow (2017), magnetohydrodynamic Falkner-Skan "wedge" flows (2014), magneto-rheological flow from an extending cylinder (2015), Hall magneto-gas dynamic generator slip flows (2016) and radiative-convective Casson slip boundary layer flows (2016, 2017). Keller's method provides unconditional stability and rapid convergence for strongly non-linear flows. It involves four key stages, summarized below.

1) Reduction of the $N^{\text {th }}$ order partial differential equation system to $N$ first order equations

2) Finite difference discretization of reduced equations

3) Quasilinearization of non-linear Keller algebraic equations

4) Block-tridiagonal elimination of linearized Keller algebraic equations

\section{Stage 1: Reduction of the $\mathrm{N}^{\text {th }}$ order partial differential equation system to $\mathbf{N}$ first order equations}

Equations (8) - (10) and (11) subject to the boundary conditions are first written as a system of first-order equations. For this purpose, we reset Equations (6) - (7) as a set of simultaneous equations by introducing the new variables

$$
\begin{aligned}
& f^{\prime}=u \\
& u^{\prime}=v \\
& \theta=s \\
& s^{\prime}=t \\
& g^{\prime}=p \\
& \left(1+\frac{1}{\beta}\right) v^{\prime}+(1+\xi \cot \xi) f v-\frac{1}{2} u^{2}+(s+N g)=\xi\left(u \frac{\partial u}{\partial \xi}-v \frac{\partial f}{\partial \xi}\right) \\
& \frac{t^{\prime}}{\operatorname{Pr}}+(1+\xi \cot \xi) f t+N_{b} \phi^{\prime} t+N_{t} t^{2}=\xi\left(u \frac{\partial s}{\partial \xi}-t \frac{\partial f}{\partial \xi}\right) \\
& \frac{p^{\prime}}{L e}+(1+\xi \cot \xi) f p+\frac{1}{L e} \frac{N_{b}}{N_{t}} t^{\prime}=\xi\left(u \frac{\partial g}{\partial \xi}-p \frac{\partial f}{\partial \xi}\right)
\end{aligned}
$$


where primes denote differentiation with respect to $\eta$. In terms of the dependent variables, the boundary conditions become:

$$
\begin{aligned}
& \text { At } \eta=0: u=0, f=0, s=1, g=1 \\
& \text { As } \eta \rightarrow \infty: u \rightarrow 0, v \rightarrow 0, s \rightarrow 0, g \rightarrow 0
\end{aligned}
$$

\section{Stage 2: Finite difference discretization of reduced boundary layer equations}

A two-dimensional computational grid (mesh) is imposed on the $\xi-\eta$ plane as sketched in Fig.2. The stepping process is defined by:

$\eta_{0}=0, \eta_{j}=\eta_{j-1}+h_{j}, j=1,2, \ldots, J, \eta_{J} \equiv \eta_{\infty}$

$\xi^{0}=0, \xi^{n}=\xi^{n-1}+k_{n}, n=1,2, \ldots, N$

where $k_{n}$ and $h_{j}$ denote the step distances in the $\xi$ (stream wise) and $\eta$ (span wise) directions respectively

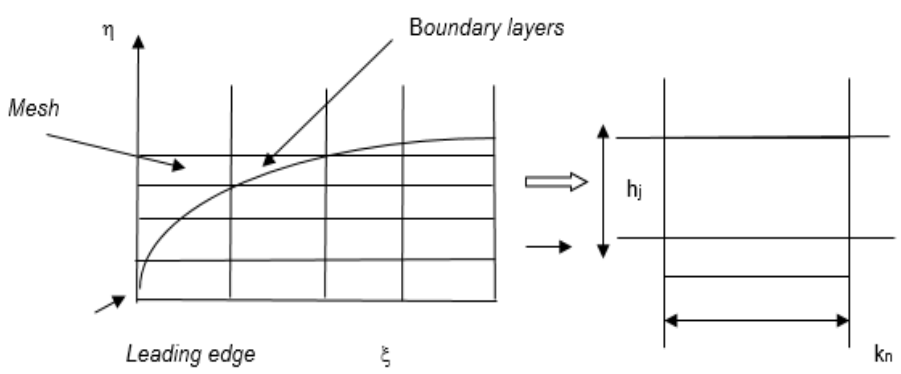

Fig. 2 Keller Box element and boundary layer mesh

If $g_{j}^{n}$ denotes the value of any variable at $\left(\eta_{j}, \xi^{n}\right)$, then the variables and derivatives of Eqns. (15) - (22) at $\left(\eta_{j-1 / 2}, \xi^{n-1 / 2}\right)$ are replaced by:

$g_{j-1 / 2}^{n-1 / 2}=\frac{1}{4}\left(g_{j}^{n}+g_{j-1}^{n}+g_{j}^{n-1}+g_{j-1}^{n-1}\right)$

$\left(\frac{\partial g}{\partial \eta}\right)_{j-1 / 2}^{n-1 / 2}=\frac{1}{2 h_{j}}\left(g_{j}^{n}-g_{j-1}^{n}+g_{j}^{n-1}-g_{j-1}^{n-1}\right)$

$\left(\frac{\partial g}{\partial \xi}\right)_{j-1 / 2}^{n-1 / 2}=\frac{1}{2 k^{n}}\left(g_{j}^{n}-g_{j-1}^{n}+g_{j}^{n-1}-g_{j-1}^{n-1}\right)$

The finite-difference approximation of equations (15) - (22) for the mid-point $\left(\eta_{j-1 / 2}, \xi^{n}\right)$, below:

$$
\begin{aligned}
& h_{j}^{-1}\left(f_{j}^{n}-f_{j-1}^{n}\right)=u_{j-1 / 2}^{n} \\
& h_{j}^{-1}\left(u_{j}^{n}-u_{j-1}^{n}\right)=v_{j-1 / 2}^{n} \\
& h_{j}^{-1}\left(g_{j}^{n}-g_{j-1}^{n}\right)=p_{j-1 / 2}^{n} \\
& h_{j}^{-1}\left(\theta_{j}^{n}-\theta_{j-1}^{n}\right)=t_{j-1 / 2}^{n}
\end{aligned}
$$

$$
\begin{aligned}
& \left(1+\frac{1}{\beta}\right)\left(v_{j}-v_{j-1}\right)+(1+\xi \cot \xi+\alpha) \frac{h_{j}}{4}\left[\left(f_{j}+f_{j-1}\right)\left(v_{j}+v_{j-1}\right)\right] \\
& -\left(\frac{1}{2}+\alpha\right) \frac{h_{j}}{4}\left(u_{j}+u_{j-1}\right)^{2}+\frac{h_{j}}{2}\left(s_{j}+s_{j-1}+N\left(g_{j}+g_{j-1}\right)\right) \\
& +\frac{\alpha h_{j}}{2} v_{j-1 / 2}^{n-1}\left(f_{j}+f_{j-1}\right)-\frac{\alpha h_{j}}{2} f_{j-1 / 2}^{n-1}\left(v_{j}+v_{j-1}\right)=\left[R_{1}\right]_{j-1 / 2}^{n-1} \\
& \frac{1}{\operatorname{Pr}}\left(t_{j}-t_{j-1}\right)+(1+\xi \cot \xi+\alpha) \frac{h_{j}}{4}\left[\left(f_{j}+f_{j-1}\right)\left(t_{j}+t_{j-1}\right)\right] \\
& -\frac{\alpha h_{j}}{4}\left[\left(u_{j}+u_{j-1}\right)\left(s_{j}+s_{j-1}\right)\right]+N b \frac{h_{j}}{4}\left[\left(t_{j}+t_{j-1}\right)\left(p_{j}+p_{j-1}\right)\right] \\
& +N t \frac{h_{j}}{4}\left(t_{j}+t_{j-1}\right)^{2}+\frac{\alpha h_{j}}{2} s_{j-1 / 2}^{n-1}\left(u_{j}+u_{j-1}\right)-\frac{\alpha h_{j}}{2} u_{j-1 / 2}^{n-1}\left(s_{j}+s_{j-1}\right) \\
& -\frac{\alpha h_{j}}{2} f_{j-1 / 2}^{n-1}\left(t_{j}+t_{j-1}\right)+\frac{\alpha h_{j}}{2} t_{j-1 / 2}^{n-1}\left(f_{j}+f_{j-1}\right)=\left[R_{2}\right]_{j-1 / 2}^{n-1} \\
& \frac{1}{L e}\left(p_{j}-p_{j-1}\right)+(1+\xi \cot \xi+\alpha) \frac{h_{j}}{4}\left[\left(f_{j}+f_{j-1}\right)\left(p_{j}+p_{j-1}\right)\right] \\
& +\frac{B}{L e}\left(t_{j}-t_{j-1}\right)-\frac{\alpha h_{j}}{4}\left[\left(u_{j}+u_{j-1}\right)\left(g_{j}+g_{j-1}\right)\right] \\
& +\frac{\alpha h_{j}}{2} s_{j-1 / 2}^{n-1}\left(u_{j}+u_{j-1}\right)-\frac{\alpha h_{j}}{2} u_{j-1 / 2}^{n-1}\left(g_{j}+g_{j-1}\right) \\
& -\frac{\alpha h_{j}}{2} f_{j-1 / 2}^{n-1}\left(p_{j}+p_{j-1}\right)+\frac{\alpha h_{j}}{2} p_{j-1 / 2}^{n-1}\left(f_{j}+f_{j-1}\right)=\left[R_{2}\right]_{j-1 / 2}^{n-1}
\end{aligned}
$$

Where the following notation applies:

$$
\begin{aligned}
& \alpha=\frac{\xi^{n-1 / 2}}{k_{n}}, \quad B=\frac{N t}{N b} \\
& {\left[R_{1}\right]_{j-1 / 2}^{n-1}=-h_{j}\left[\begin{array}{l}
\left(1+\frac{1}{\beta}\right)\left(\frac{v_{j}-v_{j-1}}{h_{j}}\right)+(1+\xi \cot \xi-\alpha)\left(f_{j-1 / 2} v_{j-1 / 2}\right) \\
+\left(\frac{1}{2}-\alpha\right)\left(u_{j-1 / 2}\right)^{2}+\left(s_{j-1 / 2}+N g_{j-1 / 2}\right)
\end{array}\right]}
\end{aligned}
$$

$\left[R_{2}\right]_{j-1 / 2}^{n-1}=-h_{j}\left[\begin{array}{l}\frac{1}{\operatorname{Pr}}\left(\frac{t_{j}-t_{j-1}}{h_{j}}\right)+(1+\xi \cot \xi-\alpha)\left(f_{j-1 / 2} t_{j-1 / 2}\right) \\ +\alpha\left(u_{j-1 / 2} s_{j-1 / 2}\right)-N b\left(p_{j-1 / 2} t_{j-1 / 2}\right)-N t\left(t_{j-1 / 2}\right)^{2}\end{array}\right]$

$$
\left[R_{3}\right]_{j-1 / 2}^{n-1}=-h_{j}\left[\begin{array}{l}
\frac{1}{L e}\left(\frac{p_{j}-p_{j-1}}{h_{j}}\right)+(1+\xi \cot \xi-\alpha)\left(f_{j-1 / 2} p_{j-1 / 2}\right) \\
+\frac{B}{L e}\left(\frac{t_{j}-t_{j-1}}{h_{j}}\right)+\alpha\left(u_{j-1 / 2} g_{j-1 / 2}\right)
\end{array}\right]
$$

The boundary conditions are

$$
f_{0}^{n}=u_{0}^{n}=0, \theta_{0}^{n}=1, u_{J}^{n}=0, v_{J}^{n}=0, \theta_{J}^{n}=0, \varphi_{0}^{n}=1, \varphi_{J}^{n}=0
$$




\section{Stage 3: Quasilinearization of non-linear Keller algebraic equations}

If we assume $f_{j-1}^{n-1}, u_{j-1}^{n-1}, v_{j-1}^{n-1}, p_{j-1}^{n-1}, s_{j-1}^{n-1}, t_{j-1}^{n-1}$, to be known for $\mathrm{O} \leq \boldsymbol{j} \leq \boldsymbol{J}$, Equations (30) - (36) comprise a system of $6 J+6$ equations for the solution of $6 J+6$ unknowns $f_{j}^{n}, u_{j}^{n}, v_{j}^{n}, p_{j}^{n}, s_{j}^{n}, t_{j}^{n}$, $j=0,1,2 \ldots, J$. This non-linear system of algebraic equations is linearized by means of Newton's method as elaborated by Keller (1970).

\section{Stage 4: Block-tridiagonal elimination of linear Keller algebraic equations}

The linearized version of eqns. (30) - (36) can now be solved by the block-elimination method, since they possess a block-tridiagonal structure since it consists of block matrices. The complete linearized system is formulated as a block matrix system, where each element in the coefficient matrix is a matrix itself. Then, this system is solved using the efficient Keller-box method. The numerical results are affected by the number of mesh points in both directions. After some trials in the $\eta$-direction (radial coordinate) a larger number of mesh points are selected whereas in the $\xi$ direction (tangential coordinate) significantly less mesh points are utilized. $\eta_{\max }$ has been set at 10 and this defines an adequately large value at which the prescribed boundary conditions are satisfied. $\xi_{\max }$ is set at 3.0 for this flow domain. Mesh independence testing is also performed to ensure that the converged solutions are correct. The computer program of the algorithm is executed in MATLAB running on a PC.

\section{VALIDATION WITH NAKAMURA DIFFERENCE SCHEME}

The present Keller box method (KBM) algorithm has been tested rigorously and benchmarked in numerous studies by the authors. However to further increase confidence in the present solutions, we have validated the general model with an alternative finite difference procedure due to Nakamura (1994). The Nakamura tridiagonal method (NTM) generally achieves fast convergence for nonlinear viscous flows which may be described by either parabolic (boundary layer) or elliptic (Navier-Stokes) equations. The coupled $7^{\text {th }}$ order system of nonlinear, multi-degree, ordinary differential equations defined by (8)-(10) with boundary conditions (11) is solved using the NANONAK code in double precision arithmetic in Fortran 90, as elaborated by Bég (2013). Computations are performed on an SGI Octane Desk workstation with dual processors and take seconds for compilation. As with other difference schemes, a reduction in the higher order differential equations, is also fundamental to Nakamura's method. The method has been employed successfully to simulate many sophisticated nonlinear transport phenomena problems e.g. magnetized bio-polymer enrobing coating flows (Bég et al. (2014)). Intrinsic to this method is the discretization of the flow regime using an equi-spaced finite difference mesh in the transformed coordinate

$(\eta)$ and the central difference scheme is applied on the $\eta$-variable. A backward difference scheme is applied on the $\xi$-variable. Two iteration loops are used and once the solution for $\eta$ has converged, the code progresses to the next $\xi$ station. The partial derivatives for $f, \theta, \phi$ with respect to $\eta$ are as explained evaluated by central difference approximations. An iteration loop based on the method of successive substitution is utilized to advance the solution i.e. march along. The finite difference discretized equations are solved in a step-by-step fashion on the $\eta$-domain in the inner loop and thereafter on the $\xi$ domain in the outer loop. For the energy and nano-particle species conservation Eqns. (9) - (10) which are second order multi-degree ordinary differential equations, only a direct substitution is needed. However a reduction is required for the third order momentum (velocity) boundary layer eqn. (8). We apply the following substitutions:

$P=f$
$Q=\theta$
$R=\phi$

The eqns. (8) - (10) then retract to:

Nakamura momentum equation:

$A_{1} P^{\prime \prime}+B_{1} P^{\prime}+C_{1} P=T_{1}$

Nakamura energy equation:

$$
A_{2} Q^{\prime \prime}+B_{2} Q^{\prime}+C_{2} Q=T_{2}
$$

Nakamura nano-particle species equation:

$$
A_{3} R^{\prime \prime}+B_{3} R^{\prime}+C_{3} R=T_{3}
$$

Here $\mathrm{Ai}=1,2,3, \mathrm{Bi}=1,2,3, \mathrm{Ci}=1,2,3$, are the Nakamura matrix coefficients, $\mathrm{Ti}=1,2,3$, are the Nakamura source terms containing a mixture of variables and derivatives associated with the respective lead variable (P, Q, R). The Nakamura Eqns. (27) - (30) are transformed to finite difference equations and these are orchestrated to form a tridiagonal system which due to the high nonlinearity of the numerous coupled, multi-degree terms in the momentum, energy, nano-particle species and motile micro-organism density conservation equations, is solved iteratively. Householder's technique is ideal for this iteration. The boundary conditions (11) are also easily transformed. Further details of the NTM approach are provided in Nakamura (1994). Comparisons are documented in Table 1 for skin friction and very good correlation is attained. Table 1 further indicates that increase in Casson viscoplastic parameter $(\beta)$ induces a strong retardation in the flow i.e. suppresses skin friction magnitudes. In both cases however positive magnitudes indicate flow reversal is not generated.

Table 1 Numerical values of skin-friction coefficient

$$
(1+1 / \beta) f^{\prime \prime}(0) \text { of } \beta \text { with }
$$

$$
\operatorname{Pr}=7.0, L e=5.0, N b=0.02=N t, \xi=1.0
$$

\begin{tabular}{|c|c|c|}
\hline$\beta$ & $\begin{array}{c}(1+1 / \beta) f^{\prime \prime}(0) \\
(\text { KBM })\end{array}$ & $\begin{array}{c}(1+1 / \beta) f^{\prime \prime}(0) \\
(N T M)\end{array}$ \\
\hline 0.7 & 0.8412 & 0.8411 \\
\hline 1.2 & 0.7605 & 0.7607 \\
\hline 1.6 & 0.7277 & 0.7261 \\
\hline 2.0 & 0.7065 & 0.7061 \\
\hline 1.0 & 0.9070 & 0.9073 \\
\hline
\end{tabular}

\section{KELLER BOX METHOD (KBM) NUMERICAL RESULTS AND DISCUSSION}

Comprehensive solutions have been obtained with KBM and are presented in Tables 1-3 and Figs. 3 to 9. The numerical problem comprises three dependent thermo-fluid dynamic variables $(f, \theta, \phi)$ and seven multi-physical control parameters, $P r, L e, \beta, N, N b, N t$. The influence of stream wise space variable $\xi$ is also investigated. In the present computations, the following default parameters are prescribed (unless otherwise stated):

$\operatorname{Pr}=7.0, L e=5.0, \beta=1.5, N=0.1, N b=0.02=N t, \xi=1.0$. 


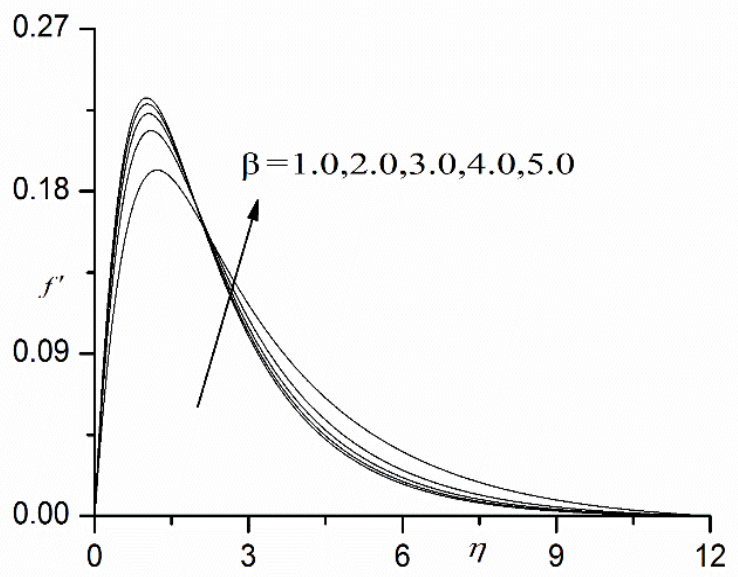

(a)

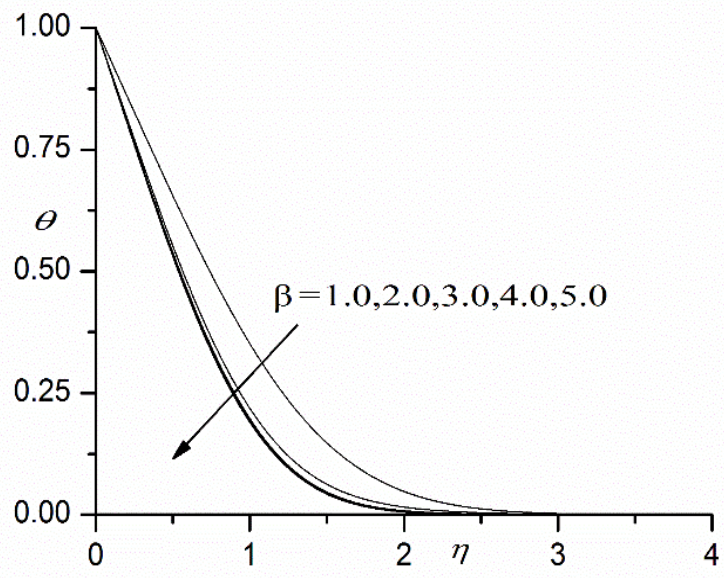

(b)

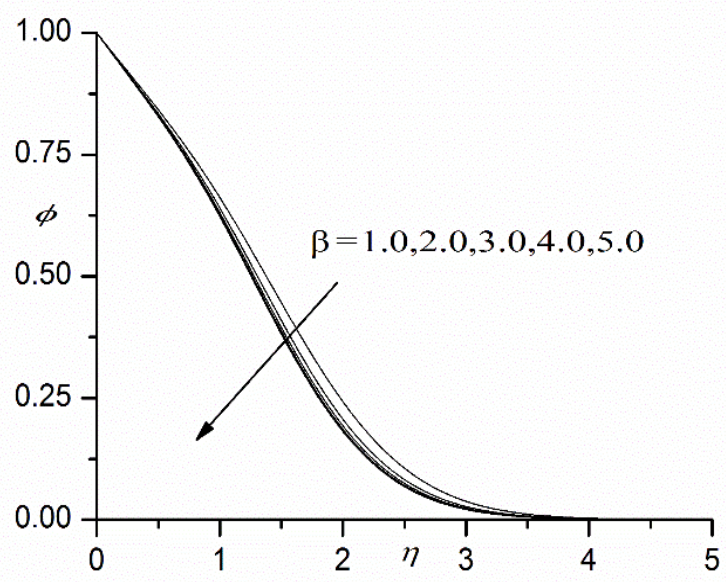

(c)

Fig. 3 Effect of $\beta$ on (a) velocity profiles, (b) temperature profiles, and (c) concentration profiles

Figs. 3a $-3 \mathrm{c}$ illustrate the effect of the Casson viscoplastic parameter, $\beta$ on velocity $\left(f^{\prime}\right)$, temperature $(\theta)$ and concentration $(\phi)$ profiles. With increasing, $\beta$ values, initially close to the sphere surface, fig. 3a shows that the flow is strongly decelerated. However, further from the surface, the converse response is induced in the flow. This may be related to the necessity for a yield stress to be attained prior to viscous flow initiation in viscoplastic shear-thinning nanofluids. Within a short distance of the sphere surface, however a strong acceleration is generated with greater Casson parameter. This serves to decrease momentum boundary layer thickness effectively. A similar observation has been reported by for example, Mustafa and Khan (2015). The viscoplastic parameter modifies the shear term $f^{\prime \prime \prime}$ in the momentum boundary layer equation (8) with an inverse factor, $1 / \beta$, and effectively assists momentum diffusion for $\beta>1$. This leads to a thinning in the hydrodynamic boundary layer and associated deceleration. The case $\beta=0$ which corresponds to a Newtonian fluid is not considered. An increase in viscoplastic parameter however decreases both temperature and nano-particle concentration magnitudes throughout the boundary layer, although the reduction is relatively weak. Thermal and nanoparticle concentration boundary layer thickness are both suppressed with greater viscoplasticity of the nanofluid.

Figs. 4a-4c depicts the effect of Prandtl number $(\mathrm{Pr})$ on the velocity $\left(f^{\prime}\right)$, temperature $(\theta)$ and nanoparticle concentration $(\phi)$

distributions with transverse coordinate $(\eta)$. Fig. 4a shows that with increasing Prandtl number there is a strong deceleration in the flow. The Prandtl number expresses the ratio of momentum diffusion rate to thermal diffusion rate. When $\mathrm{Pr}$ is unity both momentum and heat diffuse at the same rate and the velocity and thermal boundary layer thicknesses are the same. With $P r>1$ there is a progressive decrease in thermal diffusivity relative to momentum diffusivity and this serves to retard the boundary layer flow. Momentum boundary layer thickness therefore grows with Prandtl number on the surface of the sphere. It is also noteworthy that the peak velocity which is achieved close to the sphere surface is systematically displaced closer to the surface with greater Prandtl number. The asymptotically smooth profiles of velocity which decays to zero in the free stream, also confirm the imposition of an adequately large infinity boundary condition Fig. 4b indicates that increasing Prandtl number also suppresses temperatures in the boundary layer and therefore reduces thermal boundary layer thickness. Prandtl number is inversely proportional to thermal conductivity of the viscoplastic nanofluid. Higher thermal conductivity implies lower Prandtl number and vice versa. With greater Prandtl number, thermal conductivity is reduces and this inhibits thermal conduction heat transfer which cools the boundary layer.

Figs. $5 a-5 c$ illustrate the evolution of velocity, temperature and concentration functions with a variation in the Lewis number, is depicted. Lewis number is the ratio of thermal diffusivity to mass (nano-particle) species diffusivity. $L e=1$ which physically implies that thermal diffusivity of the nanofluid and species diffusivity of the nanoparticles are the same and both boundary layer thicknesses are equivalent. For Le $<1$, mass diffusivity exceeds thermal diffusivity and vice versa for Le $>1$. Both cases are examined in figs $5 \mathrm{a}-5 \mathrm{c}$. In fig $5 \mathrm{a}$, a consistently weak decrease in velocity accompanies an increase in Lewis number. Momentum boundary layer thickness is therefore increased with greater Lewis number. This is sustained throughout the boundary layer. Fig. $5 \mathrm{~b}$ shows that increasing Lewis number also depresses the temperature magnitudes and therefore reduces thermal boundary layer thickness. Therefore, judicious selection of nanoparticles during doping of polymers has a pronounced influence on velocity (momentum) and thermal characteristics in enrobing flow, since mass diffusivity is dependent on the nature of nano-particle species in the base fluid. Fig $5 \mathrm{c}$ demonstrates that a more dramatic depression in nano-particle concentration results from an increase in Lewis number over the same range as figs. 5a, b. The concentration profile evolves from approximately linear decay to strongly parabolic decay with increment in Lewis number. 


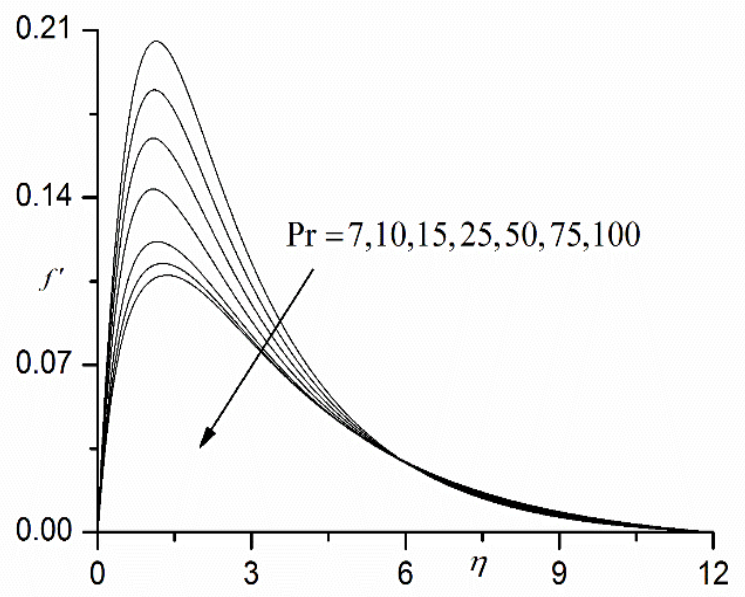

(a)

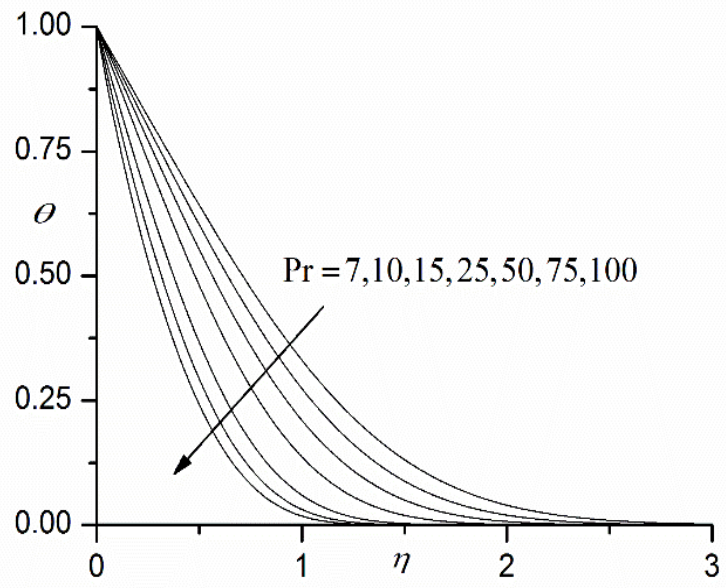

(b)

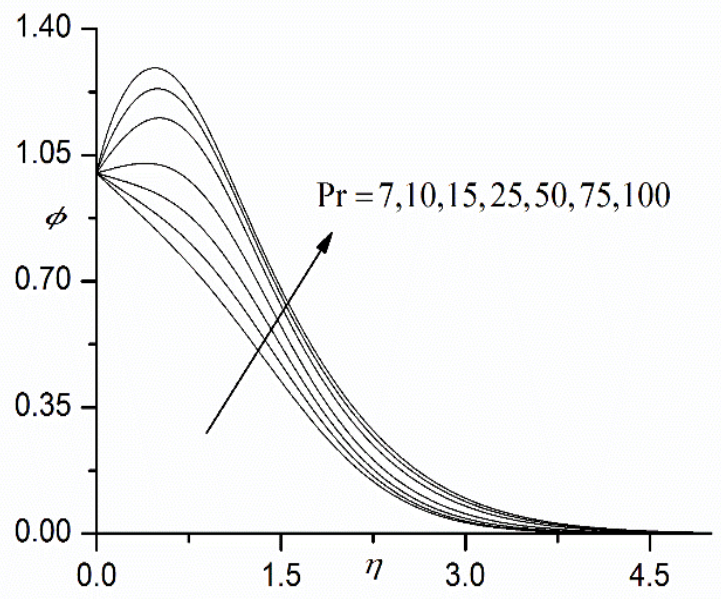

(c)

Fig. 4 Effect of $\operatorname{Pr}$ (a) velocity profiles, (b) temperature profiles, and (c) concentration profiles

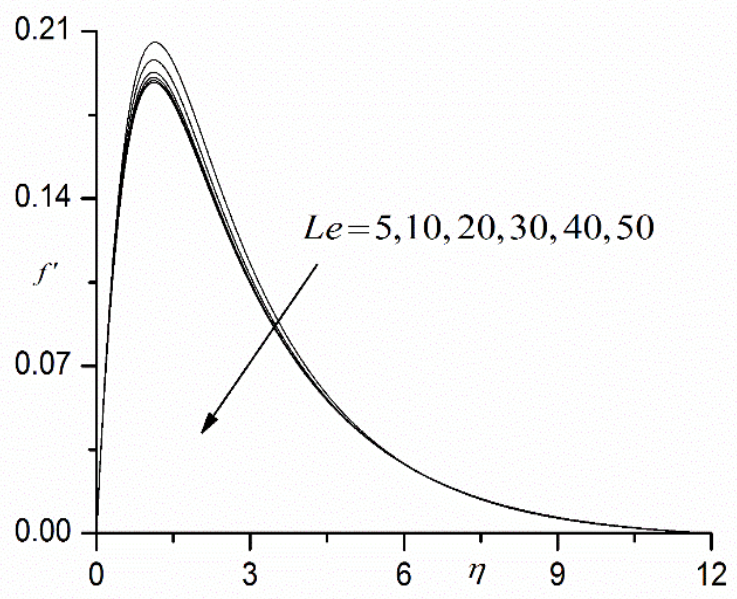

(a)

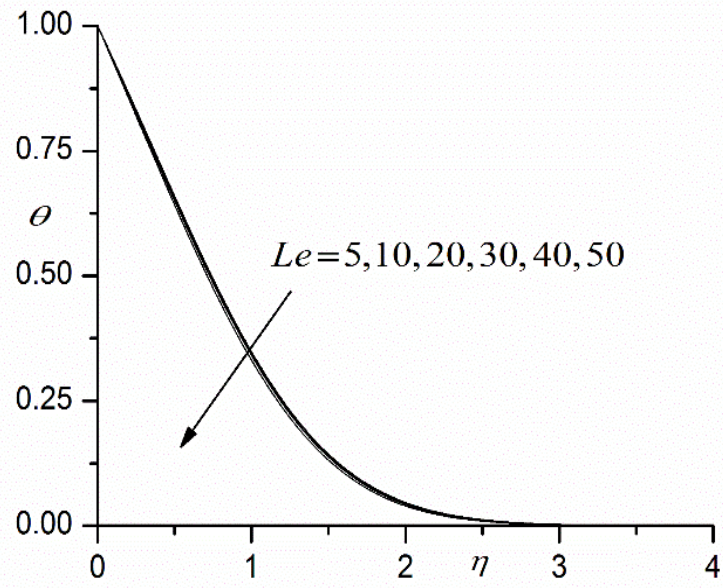

(b)

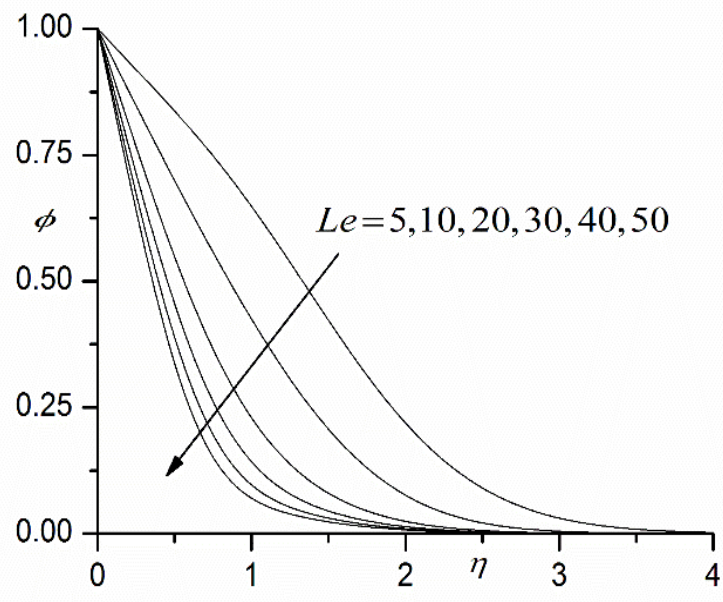

(c)

Fig. 5 Effect of $L e$ (a) velocity profiles, (b) temperature profiles, and (c) concentration profiles 


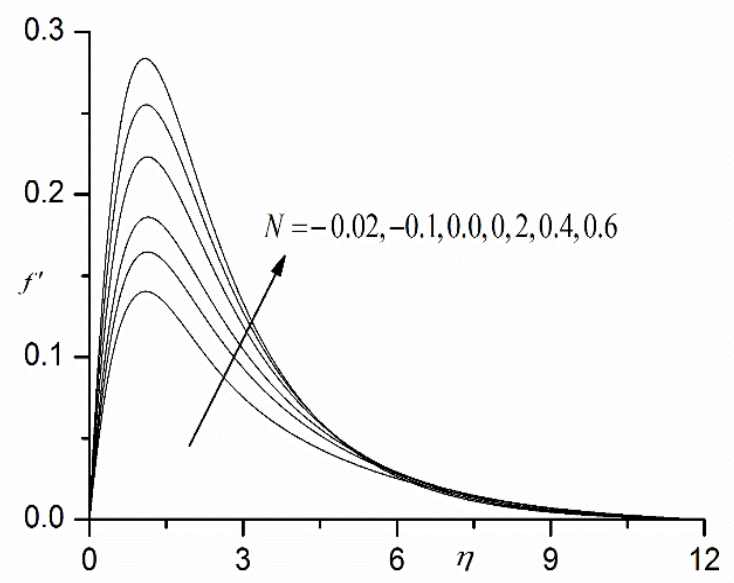

(a)

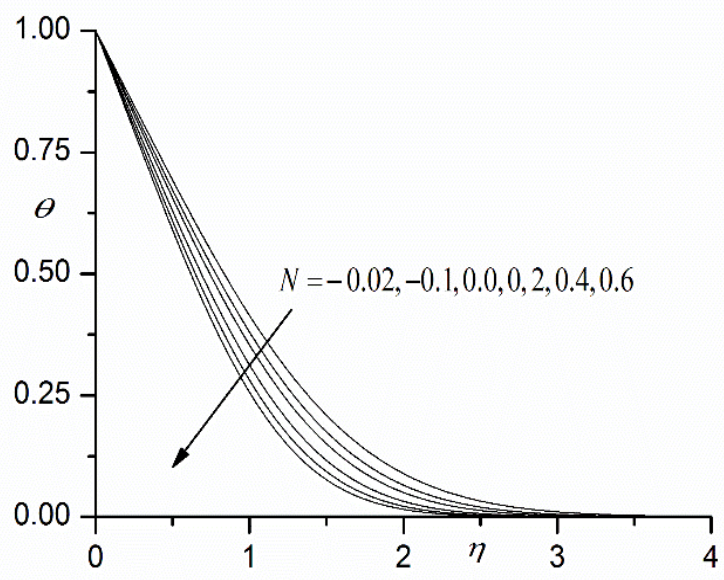

(b)

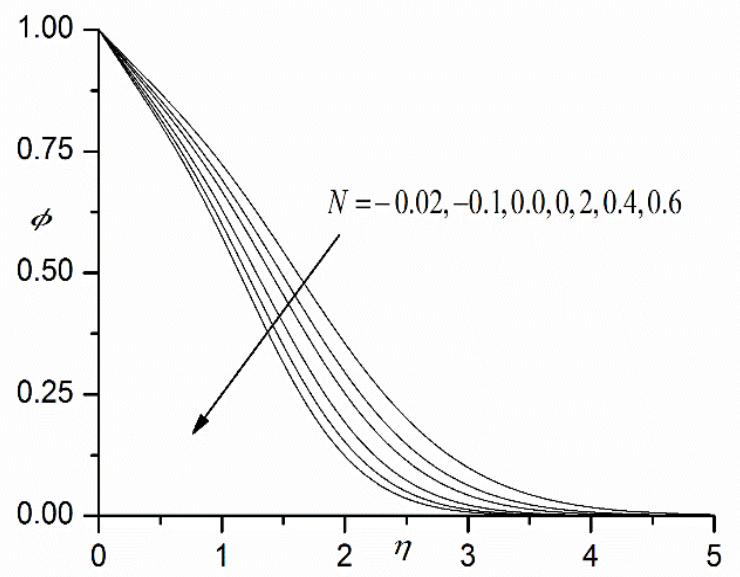

(c)

Fig. 6 Effect of $N$ on (a) velocity profiles, (b) temperature profiles, and (c) concentration profiles

Figs. $6 \mathrm{a}-6 \mathrm{c}$ present the effects of the buoyancy ratio $\mathrm{N}$ on the velocity, temperature and nano-particle concentration profiles. In general, increases in the value of $\mathrm{N}$ have the prevalent to cause more induced flow along the sphere surface. This behavior in the flow velocity increases in the fluid temperature and volume fraction species as well as slight decreased in the thermal and species boundary layers thickness as $N$ increases.

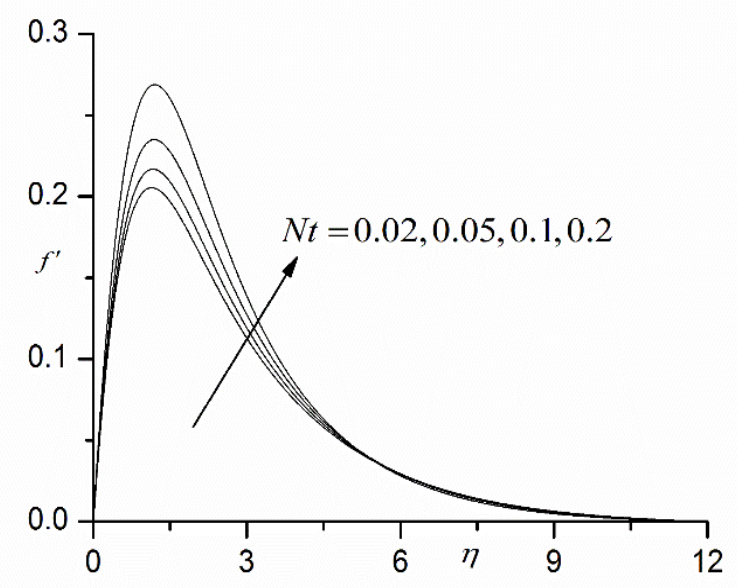

(a)

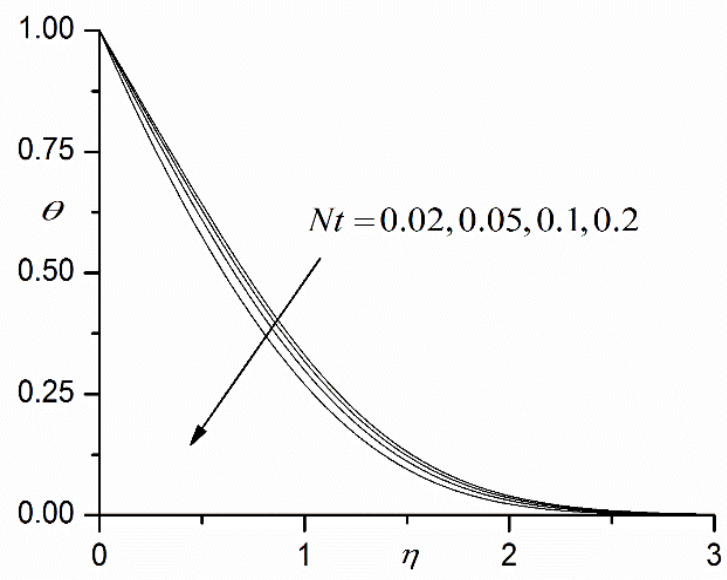

(b)

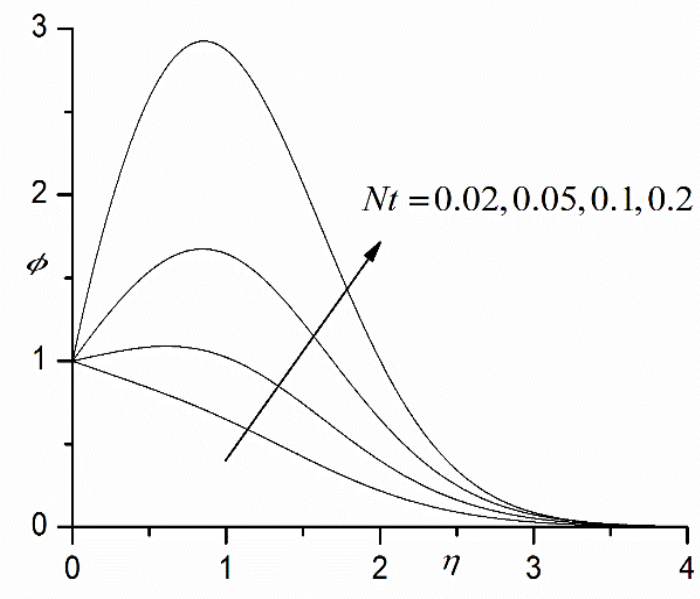

(a)

Fig. 7 Effect of $N t$ on (a) velocity profiles, (b) temperature profiles, and (c) concentration profiles 


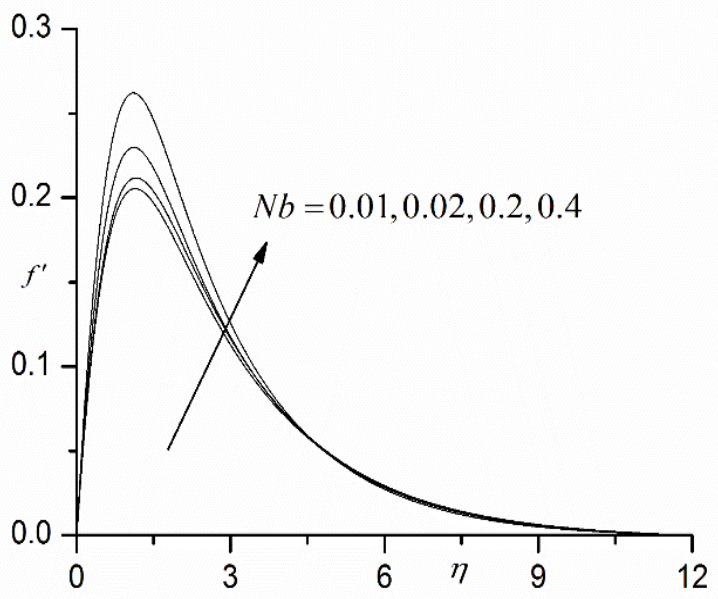

(a)

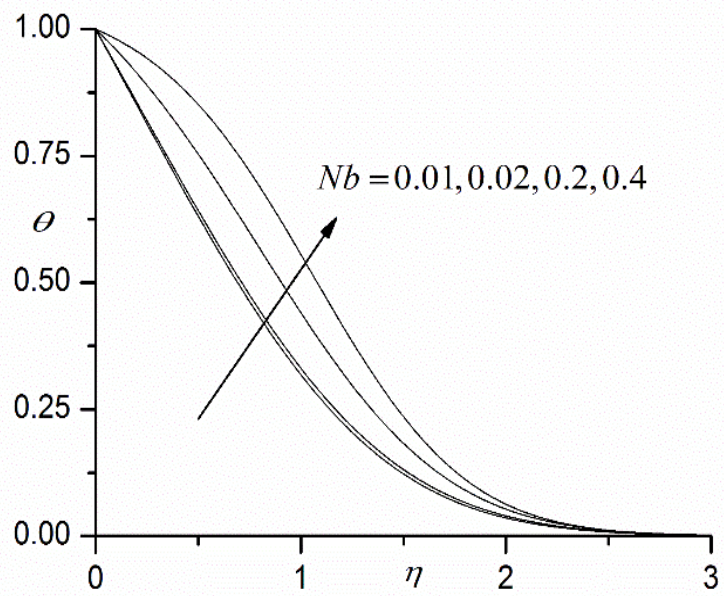

(b)

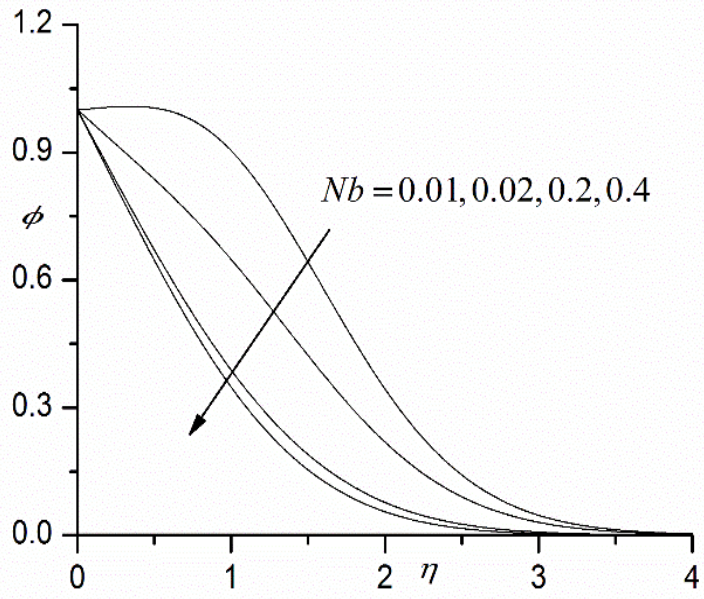

(c)

Fig. 8 Effect of $N b$ on (a) velocity profiles, (b) temperature profiles, and (c) concentration profiles

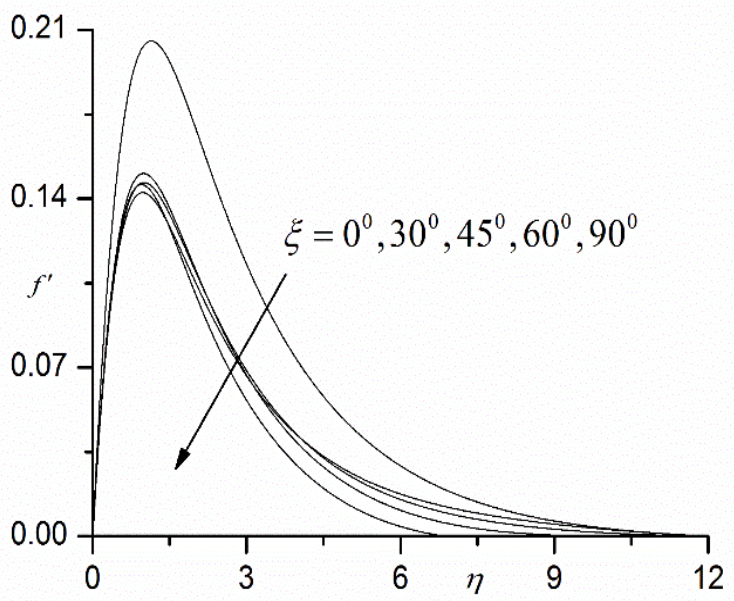

(a)

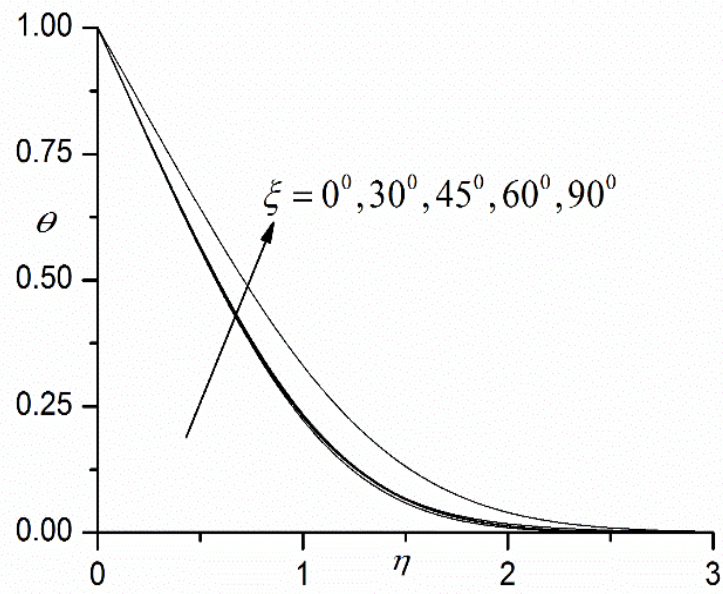

(b)

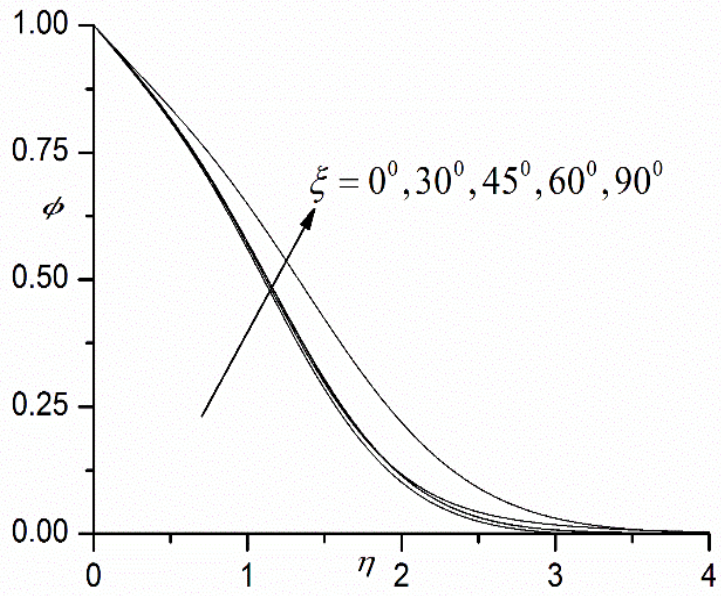

(c)

Fig. 9 Effect of $\xi$ on (a) velocity profiles, (b) temperature profiles, and (c) concentration profiles 
Figs. 7a-7c illustrates the effect of the thermophoresis parameter $(N t)$ on the velocity $\left(f^{\prime}\right)$, temperature $(\theta)$ and concentration $(\phi)$ distributions, respectively. Thermophoretic migration of nanoparticles results in exacerbated transfer of heat from the nanofluid regime to the sphere surface. This de-energizes the boundary layer and inhibits simultaneously the diffusion of momentum, manifesting in a reduction in velocity i.e. retardation in the boundary layer flow and increasing momentum (hydrodynamic) boundary layer thickness, as computed in fig. 7a. Temperature is similarly decreased with greater thermophoresis parameter (fig. 7b). Conversely there is a substantial enhancement in nano-particle concentration (and species boundary layer thickness) with greater $N t$ values. Similar observations have been made by Kunetsov and Nield (2014) and Ferdows et al. (2014) for respectively, both non-conducting Newtonian and electricallyconducting Newtonian flows.

Figs. $8 \mathrm{a}-8 \mathrm{c}$ depict the response in velocity $\left(f^{\prime}\right)$, temperature $(\theta)$ and concentration $(\phi)$ functions to a variation in the Brownian motion parameter $(\mathrm{Nb})$. Increasing Brownian motion parameter physically correlates with smaller nanoparticle diameters, as elaborated in Rana et al. (2016). Smaller values of $\mathrm{Nb}$ corresponding to larger nanoparticles, and imply that surface area is reduced which in turn decreases thermal conduction heat transfer to the sphere surface. This coupled with enhanced macro-convection within the nanofluid energizes the boundary layer and accelerates the flow as observed in fig. 8a. Similarly the energization of the boundary layer elevates thermal energy which increases temperature in the viscoplastic nanofluid. Fig 8c however indicates that the contrary response is computed in the nano-particle concentration field. With greater Brownian motion number species diffusion is suppressed. Effectively therefore momentum and nanoparticle concentration boundary layer thickness is decreased whereas thermal boundary layer thickness is increased with higher Brownian motion parameter values.

Figs. $9 a-9 c$ present the distributions for velocity, temperature and concentration fields with stream wise coordinate $\xi$, for the viscoplastic nanofluid flow. Increasing $\xi$ values correspond to progression around the periphery of the sphere, from the leading edge $(\xi=0)$. As $\xi$ increases, there is a weak deceleration in the flow (fig. 9a), which is strongest nearer the sphere surface and decays with distance into the free stream. Conversely there is a weak elevation in temperatures (fig. 9b) and nano-particle concentration magnitudes (fig. $9 \mathrm{c})$ with increasing stream wise coordinate.

Table. 2 Values of skin friction $\left(C_{f}\right)$ for different $\beta, \operatorname{Pr}, L e$ and $\xi$

\begin{tabular}{|c|c|c|c|c|c|}
\hline \multirow{2}{*}{$\beta$} & \multirow{2}{*}{$\operatorname{Pr}$} & \multirow{2}{*}{ Le } & \multicolumn{3}{|c|}{$C f$} \\
\hline & & & $\xi=0^{0}$ & $\xi=45^{0}$ & $\xi=90^{\circ}$ \\
\hline 1.0 & \multirow{5}{*}{7.0} & \multirow{10}{*}{5.0} & 0 & 0.6090 & 0.7963 \\
\hline 2.0 & & & 0 & 0.5602 & 0.7336 \\
\hline 3.0 & & & 0 & 0.5412 & 0.7086 \\
\hline 4.0 & & & 0 & 0.5306 & 0.6953 \\
\hline 5.0 & & & 0 & 0.5245 & 0.6870 \\
\hline \multirow{10}{*}{1.5} & 10 & & 0 & 0.5431 & 0.7107 \\
\hline & 25 & & 0 & 0.4646 & 0.6094 \\
\hline & 50 & & 0 & 0.4147 & 0.5446 \\
\hline & 75 & & 0 & 0.3889 & 0.5112 \\
\hline & 100 & & 0 & 0.3721 & 0.4892 \\
\hline & & 10 & 0 & 0.5656 & 0.7401 \\
\hline & & 20 & 0 & 0.5561 & 0.7278 \\
\hline & & 30 & 0 & 0.5516 & 0.7219 \\
\hline & & 40 & 0 & 0.5488 & 0.7182 \\
\hline & & 50 & 0 & 0.5468 & 0.7156 \\
\hline
\end{tabular}

Table. 3 Values of Nusselt number $(\mathrm{Nu})$ for different $\beta, \operatorname{Pr}, L e$ and $\xi$

\begin{tabular}{|c|c|c|c|c|c|}
\hline \multirow{2}{*}{$\beta$} & \multirow{2}{*}{$\operatorname{Pr}$} & \multirow{2}{*}{ Le } & \multicolumn{3}{|c|}{$N u$} \\
\hline & & & $\xi=0^{0}$ & $\xi=45^{0}$ & $\xi=90^{\circ}$ \\
\hline 1.0 & \multirow{5}{*}{7.0} & \multirow{10}{*}{5.0} & 0.6907 & 0.7872 & 0.7026 \\
\hline 2.0 & & & 0.7345 & 0.8381 & 0.7476 \\
\hline 3.0 & & & 0.7528 & 0.8655 & 0.7620 \\
\hline 4.0 & & & 0.7630 & 0.8788 & 0.7726 \\
\hline 5.0 & & & 0.7695 & 0.8843 & 0.7799 \\
\hline \multirow{10}{*}{1.5} & 10 & & 0.8011 & 0.9077 & 0.8119 \\
\hline & 25 & & 1.0901 & 1.2083 & 1.0319 \\
\hline & 50 & & 1.4885 & 1.4908 & 1.1908 \\
\hline & 75 & & 1.9317 & 1.7054 & 1.2147 \\
\hline & 100 & & 2.4835 & 1.9114 & 1.5825 \\
\hline & & 10 & 0.6946 & 0.8068 & 0.7225 \\
\hline & & 20 & 0.6756 & 0.7984 & 0.7159 \\
\hline & & 30 & 0.6665 & 0.7949 & 0.7130 \\
\hline & & 40 & 0.6610 & 0.7929 & 0.7111 \\
\hline & & 50 & 0.6571 & 0.7917 & 0.7099 \\
\hline
\end{tabular}

Table. 4 Values of Sherwood number $(S h)$ for different $\beta, \operatorname{Pr}, L e$ and $\xi$

\begin{tabular}{|c|c|c|c|c|c|}
\hline \multirow{2}{*}{$\beta$} & \multirow[b]{2}{*}{$\operatorname{Pr}$} & \multirow[b]{2}{*}{ Le } & \multicolumn{3}{|c|}{$S h$} \\
\hline & & & $\xi=0^{0}$ & $\xi=45^{0}$ & $\xi=90^{\circ}$ \\
\hline 1.0 & \multirow{5}{*}{7.0} & \multirow{10}{*}{5.0} & 0.3176 & 0.3281 & 0.2935 \\
\hline 2.0 & & & 0.3329 & 0.3451 & 0.3080 \\
\hline 3.0 & & & 0.3389 & 0.3479 & 0.3169 \\
\hline 4.0 & & & 0.3422 & 0.3485 & 0.3196 \\
\hline 5.0 & & & 0.3442 & 0.3525 & 0.3215 \\
\hline \multirow{10}{*}{1.5} & 10 & & 0.2305 & 0.2326 & 0.2086 \\
\hline & 25 & & -0.0992 & -0.1117 & -0.0587 \\
\hline & 50 & & -0.5282 & -0.4267 & -0.2493 \\
\hline & 75 & & -0.9882 & -0.6574 & -0.2894 \\
\hline & 100 & & -1.5510 & -0.8731 & -0.2085 \\
\hline & & 10 & 0.6187 & 0.6457 & 0.5748 \\
\hline & & 20 & 0.9519 & 0.9997 & 0.8923 \\
\hline & & 30 & 1.1704 & 1.2342 & 1.1023 \\
\hline & & 40 & 1.3379 & 1.4151 & 1.2641 \\
\hline & & 50 & 1.4761 & 1.5648 & 1.3979 \\
\hline
\end{tabular}

Table. 5 Values of skin friction $\left(C_{f}\right)$ for different $N b, N t, N$ and $\xi$

\begin{tabular}{|c|c|c|c|c|c|}
\hline \multirow[b]{2}{*}{$N b$} & \multirow[b]{2}{*}{$N t$} & \multirow[b]{2}{*}{$N$} & \multicolumn{3}{|c|}{$C f$} \\
\hline & & & $\xi=0^{0}$ & $\xi=45^{0}$ & $\xi=90^{\circ}$ \\
\hline 0.1 & \multirow{4}{*}{0.02} & \multirow{8}{*}{0.1} & 0 & 0.5665 & 0.7420 \\
\hline 0.2 & & & 0 & 0.5643 & 0.7395 \\
\hline 0.3 & & & 0 & 0.5637 & 0.7386 \\
\hline 0.4 & & & 0 & 0.5618 & 0.7366 \\
\hline \multirow{8}{*}{0.02} & 0.03 & & 0 & 0.5837 & 0.7648 \\
\hline & 0.05 & & 0 & 0.5975 & 0.7820 \\
\hline & 0.1 & & 0 & 0.6289 & 0.8226 \\
\hline & 0.2 & & 0 & 0.6904 & 0.9010 \\
\hline & & 0 & 0 & 0.5219 & 0.6834 \\
\hline & & 0.2 & 0 & 0.6310 & 0.8268 \\
\hline & & 0.4 & 0 & 0.7349 & 0.9618 \\
\hline & & 0.6 & 0 & 0.8333 & 1.0906 \\
\hline
\end{tabular}


Tables 2-4 presents the influence of increasing non-Newtonian Casson parameter $\beta$, Prandtl number $(P r)$ and Lewis number $(L e)$ on skin friction, heat transfer rate and mass transfer rate, along with a variation in the traverse coordinate $(\xi)$. Where heat transfer rate and mass transfer rate both are accelerate with increasing Casson parameter $\beta$, but skin friction is decreased. With increasing Prandtl number, the skin friction is generally decreased, whereas heat transfer rate is enhanced. Mass transfer rate is however decreased with increasing Prandtl number. Whereas increasing $\xi$, decreases the Skin friction but increases the Nusselt number and Sherwood number. With increasing Lewis number, skin friction and Nusselt number both are reduces, but mass transfer rate is enhanced.

Tables 5-7 presents the influence of increasing Brownian motion parameter $N b$, thermophoretic parameter $N t$ and buoyancy ratio $N$ on skin friction, heat transfer rate and mass transfer rate, along with a variation in the traverse coordinate $(\xi)$. With increasing Brownian motion parameter $\mathrm{Nb}$, the skin friction is generally increased, whereas heat transfer rate and Mass transfer rate are however increased with increasing Brownian motion parameter $\mathrm{Nb}$. With increasing buoyancy ratio $N$, the skin friction, heat transfer rate and Mass transfer rate are increased with increasing buoyancy ratio $N$. With increasing thermophoretic parameter $N t$, the skin friction is slightly increased, whereas heat transfer rate is increased. Mass transfer rate is however decreased with increasing thermophoretic parameter $N t$.

Table. 6 Values of Nusselt number $(\mathrm{Nu})$ for different $N b, N t, N$ and $\xi$

\begin{tabular}{|c|c|c|c|c|c|}
\hline \multirow{2}{*}{$N b$} & \multirow{2}{*}{$N t$} & \multirow{2}{*}{$N$} & \multicolumn{3}{|c|}{$\mathrm{Nu}$} \\
\hline & & & $\xi=0^{0}$ & $\xi=45^{0}$ & $\xi=90^{\circ}$ \\
\hline 0.1 & \multirow{4}{*}{0.02} & \multirow{8}{*}{0.1} & 0.1770 & 0.8189 & 0.7212 \\
\hline 0.2 & & & 0.2692 & 0.8313 & 0.7247 \\
\hline 0.3 & & & 0.3939 & 0.8390 & 0.7366 \\
\hline 0.4 & & & 0.5555 & 0.8454 & 0.7586 \\
\hline \multirow{8}{*}{0.02} & 0.03 & & 0.7311 & 0.8245 & 0.7323 \\
\hline & 0.05 & & 0.7573 & 0.8223 & 0.7393 \\
\hline & 0.1 & & 0.8256 & 0.8277 & 0.7472 \\
\hline & 0.2 & & 0.9782 & 0.9182 & 0.7629 \\
\hline & & 0 & 0.6895 & 0.7847 & 0.7003 \\
\hline & & 0.2 & 0.7437 & 0.8502 & 0.7580 \\
\hline & & 0.4 & 0.7877 & 0.9083 & 0.7984 \\
\hline & & 0.6 & 0.8252 & 0.9454 & 0.8415 \\
\hline
\end{tabular}

Table. 7 Values of Sherwood number $(S h)$ for different $N b, N t, N$ and $\xi$

\begin{tabular}{|c|c|c|c|c|c|}
\hline \multirow{2}{*}{$N b$} & \multirow{2}{*}{$N t$} & \multirow{2}{*}{$N$} & \multicolumn{3}{|c|}{$S h$} \\
\hline & & & $\xi=0^{0}$ & $\xi=45^{\circ}$ & $\xi=90^{\circ}$ \\
\hline 0.1 & \multirow{4}{*}{0.02} & \multirow{8}{*}{0.1} & 0.6236 & 0.6293 & 0.5625 \\
\hline 0.2 & & & 0.6759 & 0.6645 & 0.5937 \\
\hline 0.3 & & & 0.7029 & 0.6756 & 0.6043 \\
\hline 0.4 & & & 0.7222 & 0.6853 & 0.6084 \\
\hline \multirow{8}{*}{0.02} & 0.03 & & 0.1576 & 0.1526 & 0.1433 \\
\hline & 0.05 & & -0.2103 & -0.1945 & -0.1761 \\
\hline & 0.1 & & -1.3137 & -1.0594 & -0.9285 \\
\hline & 0.2 & & -4.4868 & -3.3212 & -2.3400 \\
\hline & & 0 & 0.3103 & 0.3205 & 0.2859 \\
\hline & & 0.2 & 0.3419 & 0.3534 & 0.3166 \\
\hline & & 0.4 & 0.3663 & 0.3769 & 0.3443 \\
\hline & & 0.6 & 0.3865 & 0.4034 & 0.3607 \\
\hline
\end{tabular}

\section{CONCLUSIONS}

A theoretical study has been conducted to simulate the non-Newtonian viscoplastic nanofluid boundary layer flow in enrobing processes from an isothermal sphere using the Buonjiornio formulation. The transformed momentum, heat and species boundary layer equations have been solved computationally with Keller's finite difference method. Computations have been verified with Nakamura's tridiagonal method. The present study has shown that:

(i) Increasing viscoplastic (Casson) parameter accelerates the flow and also decreases thermal and nano-particle concentration boundary layer thickness.

(ii) Increasing Prandtl number retards the flow and also decreases temperatures and nano-particle concentration values.

(iii) Increasing stream wise coordinate decelerates the flow whereas it enhances temperatures and species (nano-particle) concentrations.

(iv) Increasing Brownian motion accelerates the flow and enhances temperatures whereas it reduces nanoparticle concentration boundary layer thickness.

(v) Increasing thermophoretic parameter increasing momentum boundary layer thickness and nanoparticle boundary layer thickness whereas it reduces thermal boundary layer thickness.

(vi) Increasing Buoyancy ratio parameter enhances the flow whereas it reduces temperature and nano-particle (species) concentrations.

The current study has explored an interesting viscoplastic model for nanomaterials which are currently of interest in aerospace coating applications. Time-dependent effects have been neglected. Future studies will therefore address transient enrobing viscoplastic nanofluid transport phenomena for alternative geometries (cylinder, wedges, Cone, Plates), also of interest in aerospace materials fabrication and will be communicated imminently.

\section{ACKNOWLEDGMENT}

The authors appreciate the constructive comments of the reviewers which led to definite improvement in the paper. The authors are thankful to the management of Madanapalle Institute of Technology \& Science, Madanapalle for providing research facilities in the campus.

\section{NOMENCLATURE}

A Radius of the sphere $(m)$

C dimensional concentration

Cf skin friction coefficient

$c_{p} \quad$ specific heat at constant pressure $\left(\mathrm{kJ} / \mathrm{kg} .{ }^{\circ} \mathrm{C}\right)$

$D_{B} \quad$ Brownian diffusion coefficient

$D_{T} \quad$ thermophoretic diffusion coefficient

$f \quad$ non-dimensional stream function

$\mathrm{Gr} \quad$ Grashof number

$g \quad$ acceleration due to gravity $\left(\mathrm{m} / \mathrm{s}^{2}\right)$

$k \quad$ thermal conductivity of fluid (W/m K)

$T \quad$ temperature $(C)$

$\mathrm{Nu} \quad$ Local Nusselt Number

Sh Sherwood number

$u, v \quad$ non-dimensional velocity components

along the $x$ - and $y$-directions, respectively

$x \quad$ stream wise coordinate $(m)$

$y \quad$ transverse coordinate $(m)$

Greek Symbols

$\alpha \quad$ thermal diffusivity $\left(\mathrm{m}^{2} / \mathrm{s}\right)$

$\beta \quad$ non-Newtonian Casson parameter

$\tau \quad$ the ratio of nanoparticle heat capacity and the base fluid heat capacity

$\eta \quad$ dimensionless transverse coordinate

$v \quad$ kinematic viscosity $\left(\mathrm{m}^{2} / \mathrm{s}\right)$

$\theta \quad$ non-dimensional temperature 


$$
\begin{array}{ll}
\rho & \text { density of nanofluid }\left(\mathrm{kg} \mathrm{m}^{-3}\right) \\
\xi & \text { dimensionless steam wise coordinate } \\
\psi & \text { dimensionless stream function }
\end{array}
$$

\section{Subscripts}

$\mathrm{w} \quad$ conditions on the wall

$\infty$ free stream conditions

\section{REFERENCES}

Adhikari, A., and Sanyal, D.C., 2013, "Heat Transfer On MHD Viscous Flow over a Stretching Sheet with Prescribed Heat Flux," Bull. Int. Math. Virtual Inst., 3, 35-47.

Bég, O.A., Gaffar, S.A., Prasad, V.R., and Uddin, M.J., 2016, "Computational Solutions for Non-Isothermal, Nonlinear MagnetoConvection in Porous Media with Hall/Ion Slip Currents and Ohmic Dissipation," Eng. Science Tech., 19,377-394. http://dx.doi.org/10.1016/j.jestch.2015.08.009.

Bég, O.A., Mabood, F., and Nazru, I.M., 2015, "Homotopy Simulation of Nonlinear Unsteady Rotating Nanofluid flow from A Spinning Body," Int. J. Eng. Mathematics, Article ID 272079, 15 pages. http://dx.doi.org/10.1155/2015/272079

Bég, O.A., 2013, "NANONAK- A Finite Difference Code for Nanofluid Convection Problems of the Boundary Layer Type," Technical Report, NANO-C/5-1, 124 pages, Gort Engovation, Bradford, England and Narvik, Norway, UK.

Bég, O.A., Zueco, J., Norouzi, M., Davoodi, M., Joneidi, A.A., and Elsayed, A.F., 2014, "Network and Nakamura Tridiagonal Computational Simulation of Electrically-Conducting Biopolymer Micro-Morphic Transport Phenomena," Computers in Biology and Medicine, 44, 44-56.

http://dx.doi.org/10.1016/j.compbiomed.2013.10.026

Buongiorno, J., 2006, "Convective Transport in Nanofluids," ASME J. Heat Trans, 128, 240-250.

http://dx.doi.org/10.1115/1.2150834.

Casson, N., 1959, "Rheology of Disperse Systems," Ed. C.C. Mill, Pergamon Press, Oxford.

Chamkha, A., Subba Reddy, G.R., and Ghodeswar, K., 2010, "Nonsimilar Solution for Natural Convective Boundary Layer Flow Over a Sphere Embedded in a Porous Medium Saturated with a Nanofluid," Transp Porous Med., 86, 13-22.

http://dx.doi.org/10.1007/s11242-010-9601-0

Choi S., 1995, "Enhancing Thermal Conductivity of fluids with Nanoparticles," ASME-Publ. Fluids Engineering Division, 231, 99106.

Choi, S.U.S., and Eastman, J.A., 1995, "Enhancing Thermal Conductivity of fluids with Nanoparticles," ASME International Mechanical Engineering Congress \& Exposition, San Francisco, USA, 66, 99-105.

Damseh, R.A, Duwairi, H.M., and Al-Odat, M., 2006, "Similarity Analysis of Magnetic field and Thermal Radiation Effects on Forced Convection flow," Turkish J. Eng. Env. Sci., 30, 83-89.

http://dx.doi.org/10.1007/s40819-016-0227-y

Eswara, A.T., 2014, "MHD Falkner-Skan Boundary Layer flow past a Moving Wedge with Suction (Injection)," 19th Australasian Fluid Mechanics Conference Melbourne, Australia, 8-11.
Ferdows, M., Khan, M.S., Bég, O.A., Azad, M., and Alam, M.M., 2014, "Numerical Study of Transient Magnetohydrodynamic Radiative Free Convection Nanofluid flow from A Stretching Permeable Surface," Proc. IMechE-Part E: J. Process Mechanical Engineering, 228, 181196.

http://dx.doi.org/10.1177/0954408913493406

Hussain, T., Shehzad, S.A., Alsaedi, A., Hayat, T., and Ramzan, M., 2015, "Flow of Casson nanofluid with Viscous Dissipation and Convective Conditions: A mathematical model," J. Cent. South Univ., 22(3), 1132-1140. http://dx.doi.org/10.1007/s11771-015-2625-4

Keller, H.B., 1970, "A New Difference Method for Parabolic Problems," J. Bramble (Editor), Numerical Methods for Partial Differential Equations, Academic Press, New York, USA.

Kleinstreuer, C., and Feng, Y., 2011, "Experimental and Theoretical Studies of Nanofluid Thermal Conductivity Enhancement: A Review," Nanoscale Research Letters, 6, 229.

http://dx.doi.org/10.1186/1556-276X-6-229

Kunetsov, A.V., and Nield, D.A., 2014, "Natural Convective Boundary Layer flow of a Nanofluid Past a Vertical Plate: A Revised Model," Int. J. Thermal Sciences, 77, 126-129.

http://dx.doi.org/10.1016/j.ijthermalsci.2013.10.007

Kuznetsov, A.V., and Nield, D.A., 2010, "Natural Convective Boundary-Layer flow of A Nanofluid Past a Vertical Plate," Int. J. Thermal Sciences, 49(2), 243-247.

http://dx.doi.org/10.1016/j.ijthermalsci.2009.07.015.

Mahatha, B. K., Nandkeolyar, R., Mahto, G. K., and Sibanda, P., 2016, "A Dissipative Effects in Hydromagnetic Boundary Layer Nanofluid Flow past a Stretching Sheet with Newtonian Heating," Journal of Applied Fluid Mechanics, 9(4), 1977-1989.

Malik, M.Y, Naseer, M., Nadeem, S., and Abdul, R., 2014, "The Boundary Layer flow of Casson Nanofluid over A Vertical Exponentially Stretching Cylinder," Appl Nanosci., 4, 869-873. http://dx.doi:10.1007/s13204-013-0267-0.

Malik, M.Y, Salahuddin, T., Hussain, A., and Bilal, S., 2015, "MHD flow of Tangent Hyperbolic fluid over a Stretching Cylinder: Using Keller box method," J. Magnetism Magnetic Materials, 395, 271-276. http://dx.doi.org/10.1016/j.jmmm.2015.07.097.

Mahesh, K., and Subba Reddy, G.R., 2015, "Natural Convection Heat and Mass Transfer from a Sphere in Non-Newtonian Nanofluids," J. of Nanomaterials, Nanoengineering and Nanosystems, 228(3), 129-138. http://dx.doi.org/10.1177/1740349913494936

Mitsoulis, E., and Sofou, S., 2006, "Calendering Pseudoplastic and Viscoplastic fluids with Slip at the roll Surface," ASME J. Appl. Mech., 73, 291-299.

http://dx.doi.org/10.1115/1.2083847

Mustafa, M., and Khan, J.A., 2015, "Model for flow of Casson Nanofluid past a Non-Linearly Stretching Sheet considering magnetic field effects," AIP Advances, 5, 077148.

http://dx.doi.org/10.1063/1.4927449

Nakamura, S., 1994, "Iterative Finite Difference Schemes for Similar and Non-Similar Boundary Layer Equations," Adv. Eng. Software., 21, 123-130. 
Nagendra, N., Reddy M.V.S, and Jayaraj, B., 2008, "Peristaltic motion of a power-law fluid in an asymmetric vertical channel," Journal of Interdisciplinary Mathematics, 11(4), 505-519.

http://dx.doi.org/10.1080/09720502.2008.10700577

Prasad, V.R., Gaffar, S.A., and Bég, O.A., 2015, "Non-similar Computational Solutions for Free Convection Boundary-Layer Flow of a Nanofluid from an Isothermal Sphere in a Non-Darcy Porous Medium," J. Nanofluids, 4, 203-213.

http://dx.doi.org/10.1166/jon.2015.1149

Pham, T.V., and Mitsoulis, E., 1994, "Entry and Exit Flows of Casson Fluids," Can. J. Chem. Eng., 72, 1080-1084. http://dx.doi.org/10.1002/cjce.5450720619.

Rana, P., Bhargava, R., Bég, O.A., and Kadir, A., 2016, "Finite Element Analysis of Viscoelastic Nanofluid Flow with Energy Dissipation and Internal Heat Source/Sink Effects," Int. J. Applied and Computational Mathematics, 1-27. http://dx.doi.org/10.1007/s40819-016-0184-5

Sharma, A., Tyagi, V.V., Chen, C.R., and Buddhi, D., 2009, "Review on Thermal Energy Storage with Phase Change Materials and Applications," Renewable and Sustainable Energy Reviews., 13, 318345.

http://dx.doi.org/10.1016/j.rser.2007.10.005

Subba Rao, A., Nagendra, N., Prasad, V.R., Bég, O.A., and Rashidi, M., 2017, "Free Convection Heat and Mass Transfer of a Nanofluid Past a Horizontal Cylinder Embedded in a Non-Darcy Porous Medium," Journal of Porous Media (In press).

Subba Rao, A., Amanulla, C.H., Nagendra, N., Bég, O.A., and Kadir, A., 2017, "Hydromagnetic Flow and Heat Transfer in a Williamson Non-Newtonian Fluid from a Horizontal Circular Cylinder with Newtonian Heating," Int. J. Appl. Comput. Math., 1-21. http://dx.doi.org/10.1007/s40819-017-0304-x
Subba Rao, A., Prasad, V.R., Radhika, V.N., Bég, O.A., 2017, “Heat Transfer in Viscoplastic Boundary Layer Flow from a Vertical Permeable Cone with Momentum and Thermal Wall Slip: Numerical Study," Heat Transfer Research. (In press).

Subba Rao, A. Prasad, V.R., Harshavalli, K., and Bég, O.A., 2016, "Thermal Radiation Effects on Non-Newtonian Fluid in a Variable Porosity Regime with Partial Slip," J. Porous Media., 19(4), 313-329. http://dx.doi.org/10.1615/JPorMedia.v19.i4.30.

Subba Rao, A., Prasad, V.R., Nagendra, N., Reddy, N.B., and Bég, O.A, 2016, "Non-Similar Computational Solution for Boundary Layer Flows of Non-Newtonian Fluid from an Inclined Plate with Thermal Slip," $J$. of Appl. Fluid Mechanics, 9(2), 795-807.

Subba Rao, A., and Nagendra, N., 2015, "Thermal Radiation Effects on Oldroyd-B Nanofluid from a Stretching Sheet in a non-Darcy Porous Medium," Global J. Pure and Applied Mathematics, 11, 45-49.

Uddin, M.J., Khan, W.A., Ismail, A.I.M., and Bég, O.A., 2016, "Computational Study of Three-Dimensional Stagnation Point Nanofluid Bio Convection Flow on a Moving Surface with Anisotropic Slip and Thermal Jump Effect," ASME J. Heat Transfer., 138(10), 7 pages.

http://dx.doi.org/10.1115/1.4033581

Wong, K.V., and Deleon, O., 2010, “Applications of Nanofluid-Current and Future," Advances in Mechanical Engineering, 1, 11 pages. http://dx.doi.org/10.1155/2010/519659

Wouters, J., Lebedev, O.I., Tendeloo, G.V., Yamada, H., Sato, N., Vanacken, J., Moshchalkov, V.V., Verbiest, T., and Valev, V.K., 2011, "Preparing Polymer Films Doped with Magnetic Nanoparticles by SpinCoating and Melt-Processing can induce an in-Plane Magnetic Anisotropy," J. Appl. Phys., 109:076105.

http://dx.doi.org/10.1063/1.3572048 